\title{
Arsenotoxicidad aguda experimental en ratones Balb/c: marcadores orgánicos y compromiso esplénico
}

Alejandra Mariel Canalis ${ }^{1,2}$, Roberto Daniel Pérez ${ }^{3,4}$, Gisele Evangelina Falchini ${ }^{4}$, Elio Andrés Soria ${ }^{2,5}$

${ }^{1}$ Escuela de Nutrición, Facultad de Ciencias Médicas, Universidad Nacional de Córdoba, Córdoba, Argentina

${ }^{2}$ Consejo Nacional de Investigaciones Científicas y Técnicas, CONICET, Instituto de Investigaciones en Ciencias de la Salud, Córdoba, Argentina

${ }^{3}$ Facultad de Matemáticas, Astronomía y Física, Universidad Nacional de Córdoba, Córdoba, Argentina

${ }^{4}$ Consejo Nacional de Investigaciones Científicas y Técnicas, CONICET, Instituto de Física

"Enrique Gaviola", Córdoba, Argentina

${ }^{5}$ Cátedra de Biología Celular, Histología y Embriología, Facultad de Ciencias Médicas,

Universidad Nacional de Córdoba, Córdoba, Argentina

Introducción. El arsénico es un tóxico ambiental ampliamente diseminado en todo el mundo. En hombres y animales, diversos órganos y tejidos son blancos de sus efectos deletéreos, entre ellos, el los del sistema inmunológico.

Objetivo. Determinar la intoxicación aguda por arsénico en tejidos y células diana de ratones Balb/c in vivo.

Materiales y métodos. Se aplicó una inyección intraperitoneal de 9,5 o $19 \mathrm{mg} / \mathrm{kg} \mathrm{de}$ arsenito de sodio $\left(\mathrm{NaAsO}_{2}\right)$ o un volumen equivalente de solución fisiológica como control, en ratones Balb/c con 3 por cada grupo experimental. Tras media hora, los animales fueron sacrificados y se extrajeron bazos, timos, hígados, riñones y sangre. En cada muestra, se determinó la concentración de arsénico, polifenoles y hierro, y también, se evaluaron marcadores oxidativos, como peróxidos, productos avanzados de oxidación proteica y grupos sulfhidrilos libres. En los esplenocitos obtenidos del bazo, se determinaron la viabilidad celular y el potencial mitocondrial.

Resultados. La dosis aguda inyectada de $\mathrm{NaAsO}_{2}$ redujo la función mitocondrial de los esplenocitos, lo que derivó en muerte celular. La presencia confirmada de arsénico en las muestras de bazo y la citotoxicidad resultante, produjeron disminución de los polifenoles y de los grupos sulfhidrilos libres, y alteraron el contenido y la distribución del hierro, pero no se aumentó la producción de peróxidos.

Conclusión. Estos hallazgos aportan evidencia científica sobre los cambios en biomarcadores involucrados en la inmunotoxicidad del arsénico y ofrecen, además, una metodología para ensayar potenciales tratamientos frente a la acción deletérea de este compuesto en el sistema inmunológico.

Palabras clave: arsénico; toxicidad aguda; estrés oxidativo; sistema inmunológico, ratones.

Experimental acute arsenic toxicity in Balb/c mice: organic markers and splenic involvement

Introduction: Arsenic is an environmental toxic present worldwide. In men and animals, various organs and tissues are targets of its deleterious effects including those of the immune system.

Objective: To determine acute arsenic toxicity in tissues and target cells of Balb/c mice using an in vivo methodology.

Materials and methods: We injected Balb/c mice intraperitoneally with 9.5 or $19 \mathrm{mg} /$ $\mathrm{kg}$ of sodium arsenite $\left(\mathrm{NaAsO}_{2}\right)$, or an equivalent volume of physiological solution as a control (with 3 per experimental group). After 30 minutes, the animals were sacrificed to obtain spleen, thymus, liver, kidneys, and blood. We determined arsenic, polyphenols, and iron concentrations in each sample and we evaluated the oxidative markers (peroxides, advanced products of protein oxidation, and free sulfhydryl groups). In splenocytes from the spleen, cell viability and mitochondrial potential were also determined.

Results: The exposure to an acute dose of $\mathrm{NaAsO}_{2}$ reduced the mitochondrial function of splenocytes, which resulted in cell death. Simultaneously, the confirmed presence of arsenic in spleen samples and the resulting cytotoxicity occurred with a decrease in polyphenols, free sulfhydryl groups, and an alteration in the content and distribution of iron, but did not increase the production of peroxides. 
Conclusion: These findings provide scientific evidence about changes occurring in biomarkers involved in the immunotoxicity of arsenic and offer a methodology for testing possible treatments against the deleterious action of this compound on the immune system.

Keywords: Arsenic; acute toxicity; oxidative stress; immune system; mice.

Los compuestos derivados del arsénico son agentes químicos con una elevada toxicidad para el ser humano. Sus fuentes de procedencia son diversas y estos compuestos pueden ingresar al organismo por las vías respiratorias o la piel y, con mayor frecuencia, por su ingestión accidental, o la de agua o alimentos contaminados $(1,2)$.

El arsénico está presente en el agua como un oxianión y tiene dos estados de oxidación mayoritarios en la naturaleza: el arsenito o $\mathrm{As}^{+3}$ y el arseniato $\circ \mathrm{As}^{+5}$. Estas dos especies están en la fracción soluble del arsénico, por lo que la filtración de las muestras con un filtro de membrana de 0,45 $\mu \mathrm{m}$ permite separar el arsénico en partículas del arsénico disuelto en el agua.

En diversos estudios se han determinado los mecanismos de toxicidad del arsénico en sus distintos estados de oxidación, los cuales producen efectos deletéreos en los órganos y tejidos hemolinfáticos (3). En este sentido, se sabe que la toxicidad del arsenito $\circ \mathrm{As}^{+3}$ es varias veces mayor que la del arseniato $\circ \mathrm{As}^{+5}$ debido a su mayor reactividad y a que los compuestos arsenicales de naturaleza inorgánica poseen un poder tóxico superior al de los derivados orgánicos de este elemento (4). No obstante, todos los derivados del arsénico constituyen poderosos agentes inmunotóxicos causantes comprobados de enfermedades infecciosas y de tumores y otras condiciones crónicas, pues promueven inmunodeficiencia secundaria con compromiso de las defensas del organismo (5).

Actualmente, se sabe que entre 60 y 100 millones de personas en todo el mundo están expuestas a este contaminante y son vulnerables a sus efectos tóxicos (6), lo que lo convierte en un serio problema de salud pública en numerosos países, entre ellos la República Argentina, donde se requieren investigaciones que aporten datos significativos para avanzar en el manejo y la solución de este problema.

En este contexto, el presente estudio se centró en determinar los efectos del arsénico en los biomarcadores involucrados en su inmunotoxicidad y, en consecuencia, en el desarrollo de una metodología adecuada para el ensayo de potenciales protectores frente a su acción deletérea.

\section{Materiales y métodos}

\section{Condiciones experimentales}

Se emplearon ratones Balb/c machos de ocho semanas de edad, que se mantuvieron bajo las condiciones estándar de bioterio con alimentación e hidratación ad libitum, utilizando productos comerciales (200 $\pm 13 \mathrm{~g} / \mathrm{kg} /$ día, Cargill ${ }^{\mathrm{TM}} \mathrm{SACl}$, Argentina) y agua potable $(150 \pm 10 \mathrm{ml} / \mathrm{kg} /$ día; Aguas Cordobesas SA, Argentina), hasta el momento de la intervención.

Los animales fueron testeados y sacrificados conforme a la metodología evaluada y aprobada por el Comité Institucional para el Cuidado y Uso de Animales de Laboratorio (CICUAL) de Córdoba, Argentina, el cual acoge y reglamenta los principios y normas internacionales para el uso de animales en investigación (en este estudio: UNC-FCM-SECYT-CICUAL-2014-09-02). Según dichas normas, los animales se anestesiaron por inhalación de 
isoflurano (Piramal Healthcare, Reino Unido) para su sacrificio y, luego, se procedió a su sangrado total mediante punción cardíaca.

Se conformaron: un grupo de 3 ratones con $9,5 \mathrm{mg} / \mathrm{kg}$, otro grupo de 3 ratones con $19 \mathrm{mg} / \mathrm{kg}$ y otro grupo control de 3 ratones con $100 \mu \mathrm{l}$ de solución salina $(\mathrm{N}=9)$, que recibieron una inyección intraperitoneal empleando jeringas de $1 \mathrm{ml}(0,50 \times 15 \mathrm{~mm}-25 \mathrm{G}$ 5/88"-). Para esto, se usó arsenito de sodio $\left(\mathrm{NaAsO}_{2}\right.$, forma molecular disponible de arsénico trivalente con mayor toxicidad) (Laboratorio Anedra, Argentina), en $100 \mu \mathrm{l}$ de solución acuosa [dosis letal $\left(\mathrm{DL}_{50}\right)$ intraperitoneal en ratones: $19,0 \mathrm{mg} / \mathrm{kg}-46,3 \mu \mathrm{mol} / \mathrm{kg}$ de peso corporal) (7).

El sacrificio de los animales y su posterior autopsia se llevaron a cabo una vez transcurridos 30 minutos desde la administración de la inyección intraperitoneal, tiempo durante el cual se les mantuvo con hidratación oral ad libitum y se observó la evolución clínica de cada individuo.

Se obtuvo sangre por punción cardíaca de los animales anestesiados y, luego, se extrajeron el timo, el bazo, el hígado y el riñón, para su posterior procesado y análisis.

El bazo se dividió en dos mitades, una de las cuales se empleó para el cultivo primario de los esplenocitos. La otra mitad, junto con los demás órganos, se homogeneizó mecánicamente en $2 \mathrm{ml}$ de solución salina isotónica.

Cada muestra líquida así obtenida se dividió en dos alícuotas previa medición del contenido proteico empleando un estuche comercial (Wiener Lab Group, Argentina) para estandarizar las variables que posteriormente se estudiaron. Así, los homogenatos de tejidos se emplearon en la determinación de arsénico, hierro, peróxidos, productos avanzados de oxidación proteica y grupos sulfhidrilos libres.

Por otra parte, la fracción restante fue tratada con metanol y ácido tricloroacético al $50 \%$ (relación respectiva de volúmenes $4: 6: 0,5$ ) a $50{ }^{\circ} \mathrm{C}$ durante 30 minutos (Cicarelli, Argentina), con el fin de obtener un sobrenadante por centrifugación a $10.000 \mathrm{~g}$ durante un minuto para dosificar los polifenoles. Todas las muestras se conservaron a $-18{ }^{\circ} \mathrm{C}$ hasta el momento de su análisis.

\section{Cultivo primario de esplenocitos}

Bajo condiciones de máxima asepsia, se disgregó mecánicamente cada muestra esplénica en $2 \mathrm{ml}$ de solución hemolítica. La suspensión celular obtenida se recogió en un tubo cónico estéril, se centrifugó para recuperar el precipitado y se resuspendió en $10 \mathrm{ml}$ de medio de cultivo RPMl 1640 sin rojo fenol con $10 \%$ de suero fetal bovino, $2 \mathrm{~g} / \mathrm{L}$ de bicarbonato de sodio, $10 \mathrm{mg} / \mathrm{L}$ de ciprofloxacina y $3,25 \mu \mathrm{l} / \mathrm{L}$ de mercaptoetanol.

Por último, se contabilizaron las células en una cámara de Neubauer y los resultados se expresaron como células/ $\mu$ l. Las suspensiones celulares se mantuvieron a $37{ }^{\circ} \mathrm{C}$ en ambiente estéril con $5 \%$ de $\mathrm{CO}_{2}$ hasta su análisis.

\section{Determinaciones}

Arsénico. Se determinó su presencia en muestras de bazo y riñón (este último por su rol en la excreción de este mineral) mediante fluorescencia de rayos $X$. Para ello, se depositaron $30 \mu \mathrm{l}$ del homogenato de cada muestra agregando un estándar interno de cloruro de estroncio sobre una película de 
celulosa de $0,1 \mathrm{~mm}$ de espesor. Posteriormente, cada una de las muestras fue irradiada con rayos $X$ de $17,44 \mathrm{keV}$ seleccionados mediante un monocromador de cristal en un tubo de rayos $X$ de $3 \mathrm{~kW}$ de potencia con foco lineal de $12 \mathrm{~mm} \mathrm{X}$ 0,4 mm y un ánodo de molibdeno (modelo PW2275/20, Philips, Países Bajos).

La radiación característica emitida por el arsénico se registró con un detector de estado sólido dispersivo en energía de cristal de silicio (modelo XT, marca MOXTEK Inc., Estados Unidos). La preparación de la muestra delgada combinada con la excitación monocromática permitió minimizar el ruido espectral, mejorando considerablemente el límite de detección de la técnica y alcanzando los 0,2 ppm p/p para el As (8).

\section{Viabilidad celular}

La metodología y las condiciones óptimas de reacción se ensayaron y se establecieron previamente. Posteriormente, las suspensiones celulares se incubaron en una placa de 96 pozos, en oscuridad y a $37^{\circ} \mathrm{C}$, con una solución de $0,05 \mathrm{mg} / \mathrm{ml}$ de resazurina en proporción de 1:100 v/v. Pasadas cinco horas, se procedió a medir la absorbancia a $600 \mathrm{~nm}$ usando un multilector de microplacas Multi-GloMax ${ }^{\mathrm{TM}}$ (Promega Corp., USA) y se calcularon los niveles de viabilidad celular como porcentaje de absorbancia con respecto al grupo de control (\%) luego de estandarizar los valores obtenidos por el número de células contenido en cada suspensión celular (9).

\section{Polifenoles}

Mediante la técnica de Folin-Ciocalteu, se incorporaron solución de Folin $2 \mathrm{~N}$, agua destilada y solución saturada de bicarbonato de sodio a los sobrenadantes ácido-metanólicos de las muestras, los cuales se habían sembrado previamente en una placa de 96 pozos en proporción de 1:6:2:1 v/v/v/v. La mezcla resultante se incubó en oscuridad durante 30 minutos a $37^{\circ} \mathrm{C}$, tras lo cual se midió la absorbancia a $750 \mathrm{~nm}$ y se calculó el contenido de polifenoles por interpolación de las lecturas obtenidas con una curva estándar de ácido gálico (0-0,1 mg/ $\mathrm{ml}$ ) expresada en $\mathrm{mg}$ de proteína (EAG $\mu \mathrm{g} / \mathrm{mg}$ de proteína, proteína , con EAG como equivalentes de ácido gálico) (10).

\section{Hierro}

Este se determinó en los homogenatos de las muestras midiendo por espectrofotometría a 570-640 nm la formación de un complejo azul-violáceo a partir de los cationes ferrosos con 3-(2-piridil)-5,6-bis-2(sulfofuril)-1,2,3-triazina (fereno) (Ferroquant, GT Lab, Argentina). Los resultados se expresaron como $\mu \mathrm{g}$ de hierro por mg de proteína, para lo cual se empleó como estándar la solución de sales ferrosas de $100 \mu \mathrm{g} / \mathrm{dl}$ provista por el estuche comercial (11).

\section{Peróxidos acuosos y lipídicos}

Cada muestra se sometió a reacción con la solución cromógena (1:10 v/v) y se incubó durante 30 minutos a temperatura ambiente. Para el peróxido acuoso, dicha solución consistió en $25 \mathrm{mM}$ de sulfato de amonio ferroso en $2,5 \mathrm{M}$ de ácido sulfúrico reconstituido con $100 \mathrm{mM}$ de sorbitol y $125 \mu \mathrm{M}$ de naranja de xilenol. Para el peróxido lipídico), el sulfato de amonio ferroso se reconstituyó con $4 \mathrm{mM}$ de hidroxitolueno butilado y $125 \mu \mathrm{M}$ de naranja de xilenol en metanol al 90 \% (Sigma-Aldrich Co., USA). Las concentraciones de ambos peróxidos se calcularon como porcentajes de absorbancia a 540 $\mathrm{nm}$ con respecto al grupo de control, tras restar el blanco correspondiente y estandarizar según el contenido proteico (12). 


\section{Productos avanzados de oxidación proteica}

Esto se midieron mediante espectrofotometría a $340 \mathrm{~nm}$ en condiciones acídicas y en presencia de yoduro de potasio, siguiendo la reacción de yoduro a diyodo que provocan los productos avanzados de oxidación proteica y utilizando como patrón de referencia la cloramina T. Para ello, se colocó la muestra en una placa de 96 pozos con $0,015 \mathrm{M}$ de solución PBS, $16 \mathrm{M}$ de yoduro de potasio (IK 1) y ácido acético en una relación de 4:16:1:2. La concentración de estos productos se calculó con base en la ecuación de la curva del estándar y se expresó como mg equivalentes de cloramina T por mg de proteína (13).

\section{Grupos sulfhidrilos libres}

Para determinarlos en las muestras, se utilizó el reactivo de Ellman, 5, 5'-ditio-bis- (ácido 2-nitrobenzoico) (Sigma-Aldrich Co., USA), también conocido como DTNB. La técnica necesitó ser desarrollada y puesta a punto, para lo cual se preparó una solución madre de $10 \mathrm{mM}$ de DTNB, empleando DMSO como solvente que luego se diluyó 100 veces con tris- $\mathrm{HCl} 0,1 \mathrm{M} \mathrm{pH} \mathrm{7,5}$ para obtener una solución de $0,1 \mathrm{mM}$ cada vez que fue necesario.

De esta manera, $190 \mu \mathrm{l}$ de la solución diluida se incorporaron a los homogenatos de muestras $(10 \mu \mathrm{l})$ en una placa de 96 pozos y se incubaron durante una hora a temperatura ambiente antes de medir la absorbancia en el espectrofotómetro (412 nm). Los grupos sulfhidrilo se calcularon como $\mathrm{mg}$ de $\mathrm{N}$-acetilcisteína por $\mathrm{mg}$ de proteína, para lo cual se restaron los blancos correspondientes a las lecturas obtenidas y se interpolaron los valores estandarizados por proteínas contenidas en la muestra con una curva del estándar $\left(R^{2}>0,97\right)$ realizada con $0,032-1,02 \mu \mathrm{g}$ de $\mathrm{N}$-acetilcisteína (SigmaAldrich Co., USA) (7).

\section{Determinación del potencial mitocondrial}

Se incubaron las muestras a $37^{\circ} \mathrm{C}$ durante 15 minutos bajo condiciones de oscuridad en $148 \mu \mathrm{l}$ de suspensión celular con $2 \mu \mathrm{l}$ de reactivo de yoduro de 3,3'dihexiloxacarbocianina (Sigma-Aldrich Co., USA) preparado en dimetilsulfóxido (concentración final del fluoróforo de $40 \mathrm{nM}$ ) para, luego, leer la absorbancia a $485 \mathrm{~nm}$. Tras estandarizar por conteo celular, los resultados se expresaron como porcentaje de área con respecto al grupo de control.

\section{Análisis estadístico}

Los resultados obtenidos a partir de las distintas determinaciones se expresaron como media \pm error estándar con el programa estadístico InfoStat 2018 (estadística descriptiva). Para establecer el efecto en las muestras animales, se empleó un análisis de varianza seguido por la prueba de Fisher $(p<0,05)(14)$.

\section{Resultados}

\section{Acumulación tisular de arsénico}

Considerando los límites de detección de la metodología aplicada, la presencia de arsénico se confirmó en las muestras de bazo y riñón de los animales tratados con $\mathrm{NaAsO}_{2}(>0,2 \mathrm{ppm}$ p/p), en tanto que, en aquellas del grupo de control, se determinaron su ausencia o sus valores no detectables $(<0,2 \mathrm{ppm} \mathrm{p} / \mathrm{p})$. Estos hallazgos confirman la acumulación de arsénico en los grupos inyectados con $\mathrm{NaAsO}_{2}$. 


\section{Disminución de la viabilidad celular}

El análisis de los datos por regresión lineal indicó un descenso de la viabilidad celular dependiente de la concentración de arsénico $\left(R^{2}=0,7 ; p<0,0001\right)$, siendo significativa estadísticamente la reacción ante la $\mathrm{DL}_{50}$ intraperitoneal $(19 \mathrm{mg} / \mathrm{kg}$ de $\mathrm{NaAsO}_{2}$ ) comparada con la del control $(46,95 \% ; \mathrm{p}<0,05)$ (figura 1).

Según los resultados obtenidos, se hicieron las siguientes cuantificaciones en las muestras de bazo y timo del grupo de control y las del grupo que recibió la $\mathrm{DL}_{50}$ de $19 \mathrm{mg} / \mathrm{kg}$ de $\mathrm{NaAsO}_{2}$ intraperitoneal. Posteriormente, las pruebas se repitieron en las muestras de hígado y riñón de los mismos grupos.

\section{Compromiso de los polifenoles biodisponibles}

La concentración de polifenoles dosificada en los bazos (0,33 \pm 0,07 EAG $\mu \mathrm{g} / \mathrm{mg}$ de proteína) y timos (0,06 $\pm 0,03$ EAG $\mu \mathrm{g} / \mathrm{mg}$ de proteína) del grupo que recibió arsénico fue inferior comparada con la del grupo control $(0,59 \pm 0,11$ EAG $\mu \mathrm{g} / \mathrm{mg}$ de proteína), verificándose una depleción en la biodisponibilidad de estos antioxidantes provenientes de la dieta, la cual resultó estadísticamente significativa en el timo. Por otra parte, no se observaron diferencias de la sangre y los órganos metabólicos entre los grupos experimentales (figura 2). Estos hallazgos demuestran un compromiso de la biodisponibilidad de los polifenoles por la incorporación de arsénico al organismo.

\section{Reducción variable del hierro tisular}

La inyección intraperitoneal de la $\mathrm{DL}_{50}$ de arsenito de sodio condujo a una reducción significativa de la concentración total de hierro en el bazo $(0,086 \pm 0,012 \mu \mathrm{g}$ de hierro/mg de proteína; $p<0,05)$, comparada con la del control $(0,150 \pm 0,030 \mu \mathrm{g}$ de hierro/mg de proteína), lo que da cuenta de una alteración mediada por el arsénico en el contenido y la distribución del hierro. No se observaron variaciones en la concentración del metal medido en los timos, los riñones y los hígados de los animales de los dos grupos experimentales comparados (figura 3 ).

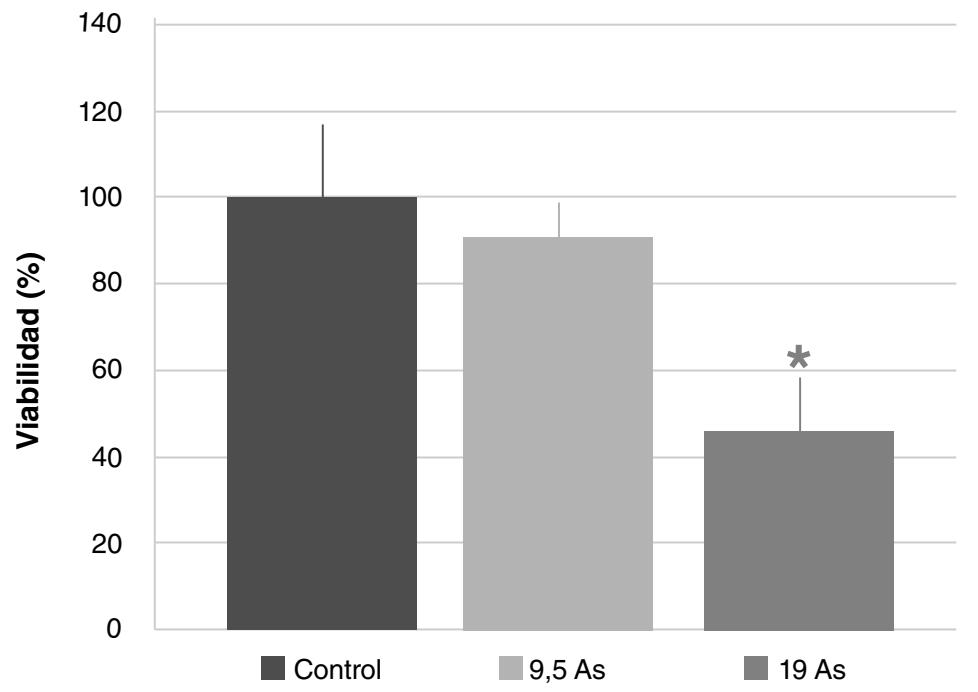

Figura 1. Viabilidad de esplenocitos obtenidos por cultivo primario de bazo de ratones Balb/c sometidos a las siguientes condiciones experimentales: $0 \mathrm{mg} / \mathrm{kg}$ de $\mathrm{NaAsO}_{2}$ (control), 9,5 mg/kg de $\mathrm{NaAsO}_{2}$ intraperitoneal (9,5 As), $19 \mathrm{mg} / \mathrm{kg}$ de $\mathrm{NaAsO}_{2}$ intraperitoneal (19 As). Los valores se expresan como medias (\% de área según control) $\pm E^{2}(n>3)$.

${ }^{*} \mathrm{p}<0,05$ 


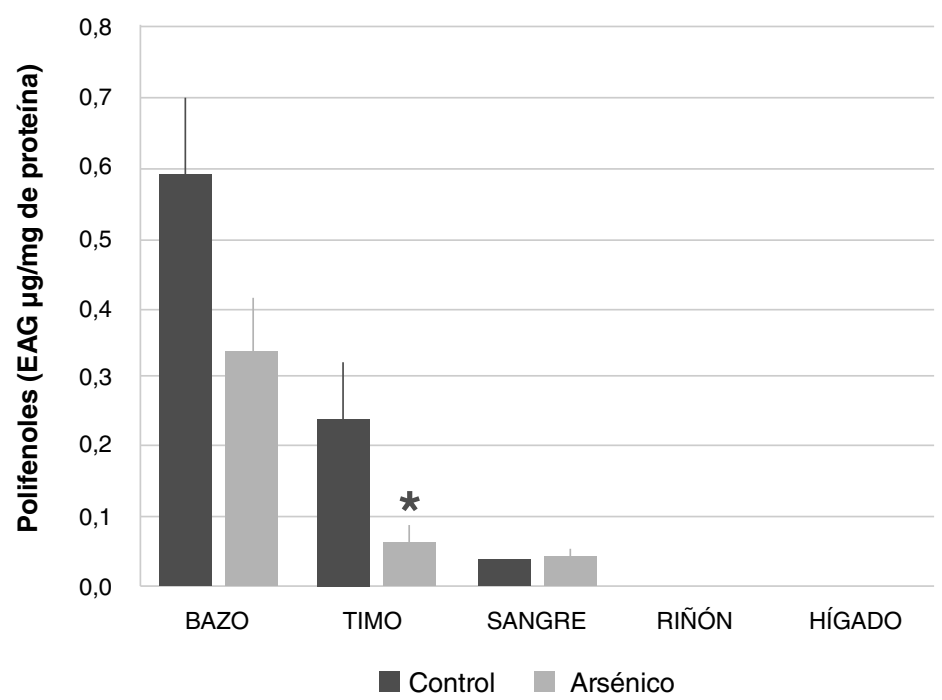

Figura 2. Concentración de polifenoles en bazo, timo, sangre, riñón e hígado de ratones Balb/c sometidos a las siguientes condiciones experimentales: $0 \mathrm{mg} / \mathrm{kg}$ de $\mathrm{NaAsO}_{2}$ (control), $19 \mathrm{mg} /$ $\mathrm{kg}$ de $\mathrm{NaAsO}_{2}$ intraperitoneal (arsénico). Los valores se expresan como medias (EAG $\mu \mathrm{g} / \mathrm{mg}$ de proteína) $\pm E E(n>3)$.

${ }^{*} p<0,05$

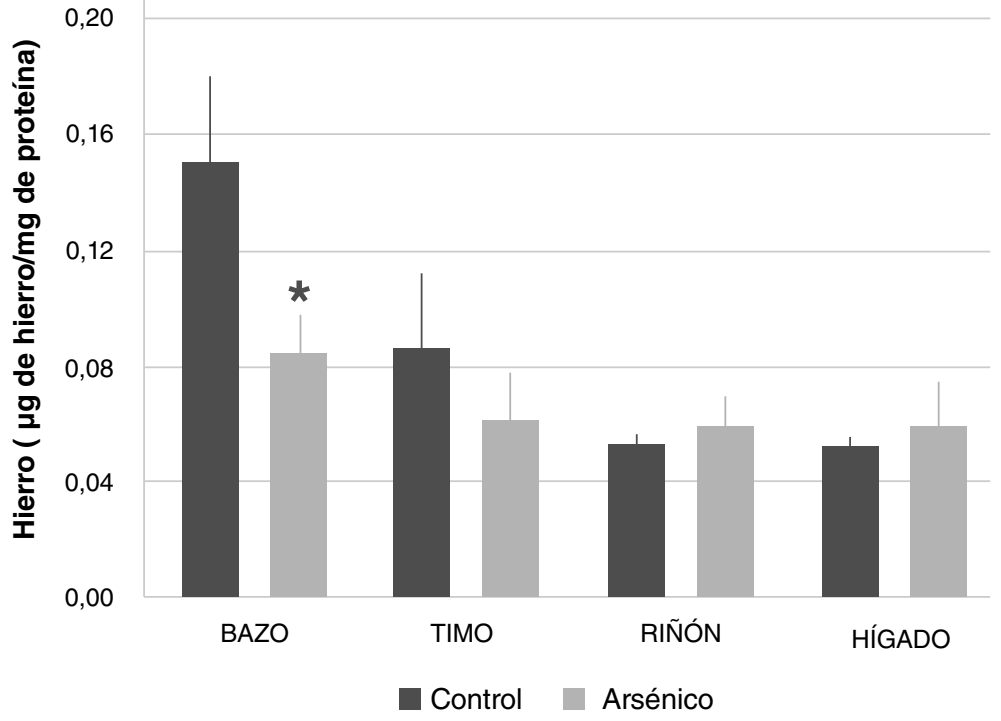

Figura 3. Concentración de hierro en bazo, timo, riñón e hígado de ratones Balb/c sometidos a las siguientes condiciones experimentales: $0 \mathrm{mg} / \mathrm{kg}$ de $\mathrm{NaAsO}_{2}$ (control), $19 \mathrm{mg} / \mathrm{kg}$ de NaAsO intraperitoneal (arsénico). Los valores se expresan como medias ( $\mu \mathrm{g}$ de hierro/mg de proteína) \pm EE $(n>3)$.

* $p<0,05$

\section{Oxidación renal sin compromiso de otros órganos}

El análisis de los resultados no evidenció diferencias significativas en la producción de peróxidos acuosos y lipídicos entre el grupo control y aquel con arsénico. Solo en los riñones del grupo con arsénico se observó un incremento en la producción de peróxido acuoso del 165,85 \% con respecto al control $(p<0,05)$ (figura 4$)$.

Estos valores no evidenciaron diferencias significativas al evaluar y comparar los grupos de control y con arsénico en cuanto a la formación de 
productos avanzados de oxidación proteica que tiene lugar como resultado de la oxidación de macromoléculas de naturaleza proteica (figura 5).

La evaluación simultánea de estos datos evidenció que la dosis aguda empleada solo indujo estrés oxidativo en el riñón, por lo que no sería esta la causa del descenso de viabilidad observado en los esplenocitos.

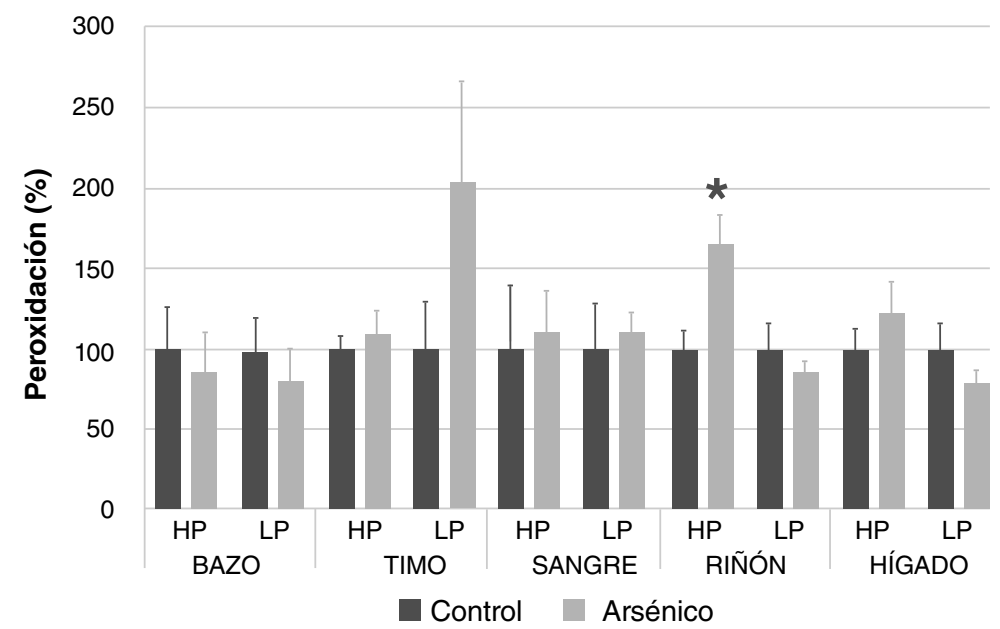

HP: hidroperóxidos; LP: lipoperóxidos

Figura 4. Formación de hidroperóxidos y lipoperóxidos de bazo, timo, sangre, riñón e hígado de ratones Balb/c sometidos a las siguientes condiciones experimentales: $0 \mathrm{mg} / \mathrm{kg}$ de $\mathrm{NaAsO}_{2}$ (control), $19 \mathrm{mg} / \mathrm{kg}$ de $\mathrm{NaAsO}_{2}$ lipoperóxidos (arsénico). Los valores se expresan como medias (\% de área según control) $\pm E E(n>3)$.

${ }^{*} p<0,05$

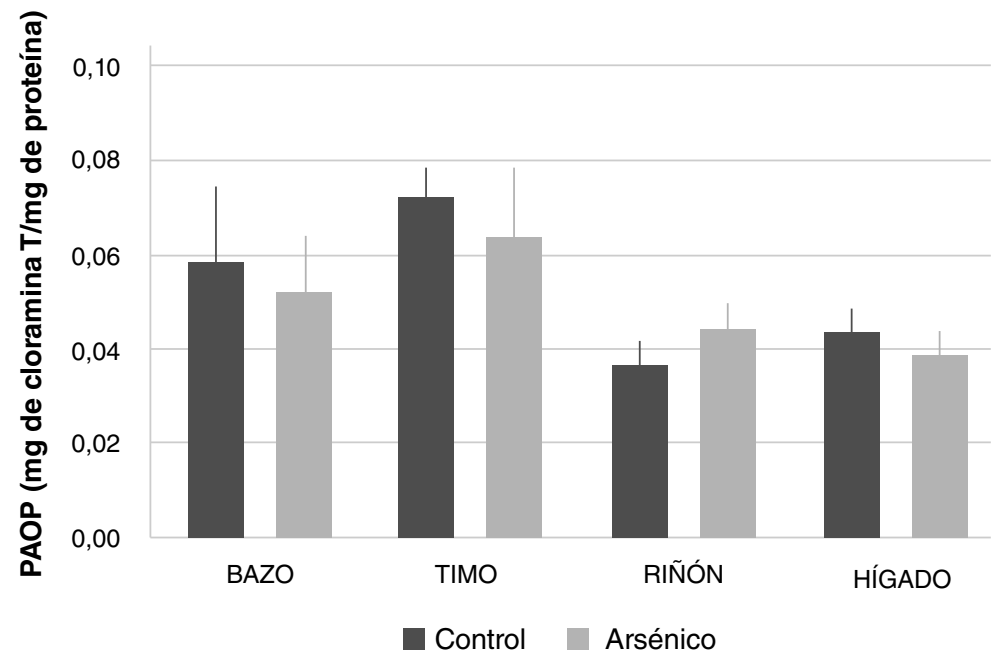

Figura 5. Formación de productos avanzados de oxidación proteica en bazo, timo, riñón e hígado de ratones Balb/c sometidos a las siguientes condiciones experimentales: $0 \mathrm{mg} / \mathrm{kg}$ de $\mathrm{NaAsO}_{2}$ (control), $19 \mathrm{mg} / \mathrm{kg}$ de $\mathrm{NaAsO}_{2}$ intraperitoneal (arsénico). Los valores se expresan como medias (mg de cloramina $\mathrm{T} / \mathrm{mg}$ de proteína) $\pm \mathrm{EE}(\mathrm{n}>3)$.

* $p<0,05$

\section{Efecto diferencial en los grupos sulfhidrilos libres}

Tras la inyección intraperitoneal de arsenito de sodio, la concentración de sulfhidrilos libres en el bazo tendió a disminuir $(0,0072 \pm 0,0014 \mathrm{mg}$ de $\mathrm{N}$-acetilcisteína/mg de proteína) con respecto al control $(0,0142 \pm 0,0014 \mathrm{mg}$ de $\mathrm{N}$-acetilcisteína/mg de proteína), aunque no representó una reducción 
estadísticamente significativa. En el timo, por el contrario, se presentó una tendencia al incremento de la concentración de los sulfhidrilos libres en las muestras obtenidas del grupo con arsénico $(0,037 \pm 0,009 \mathrm{mg}$ de $\mathrm{N}$-acetilcisteína/mg de proteína) comparado con el control $(0,015 \pm 0,002$ $\mathrm{mg}$ de $\mathrm{N}$-acetilcisteína/mg de proteína). Además, en las muestras de sangre, riñones e hígados, no se observaron variaciones significativas entre los resultados de ambos grupos (figura 6). Los hallazgos tras la medición de este biomarcador evidenciaron una interacción del arsénico administrado con los sulfhidrilos libres disponibles en el bazo y el timo.

\section{Disminución del potencial mitocondrial}

Se observó una reducción del 23,08 \% en el potencial mitocondrial de los esplenocitos obtenidos de los animales que recibieron la $\mathrm{DL}_{50}$ de arsenito de sodio. En este sentido, el análisis estadístico de los datos disponibles determinó un efecto inverso o negativo dependiente de la dosis del arsénico $(p=0,0632)$, lo que explica la caída en la función mitocondrial correlacionada con el incremento de este metal en el organismo.

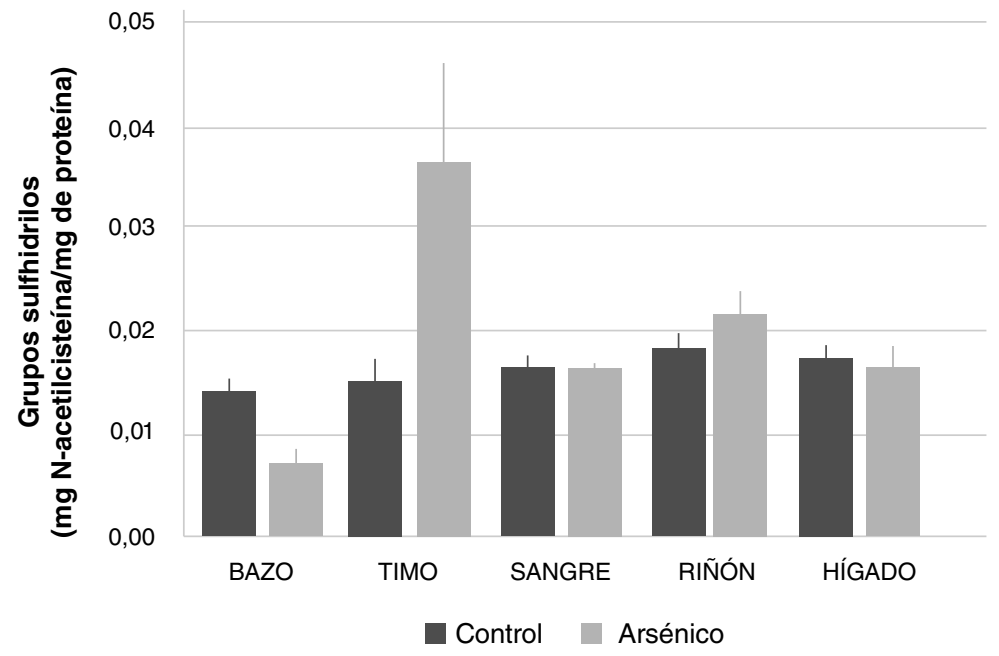

Figura 6. Concentración de grupos sulfhidrilos en bazo, timo, sangre, riñón e hígado de ratones Balb/c sometidos a las siguientes condiciones experimentales: $0 \mathrm{mg} / \mathrm{kg}$ de $\mathrm{NaAsO}_{2}$ (control), 19 $\mathrm{mg} / \mathrm{kg}$ de $\mathrm{NaAsO}_{2}$ ip (arsénico). Los valores se expresan como medias (mg de N-acetilcisteína/ $m g$ de proteína $) \pm E E(n>3)$.

${ }^{*} p<0,05$

\section{Discusión}

Tras el análisis de los resultados obtenidos, pudo confirmarse la presencia de arsénico en las muestras de bazo y riñón de los animales inyectados con arsenito de sodio y su ausencia en los mismos tejidos provenientes del grupo de control, lo cual confirma que estos son acumuladores de compuestos arsenicales $(15,16)$. Además, la presencia de arsénico en el bazo tras la administración de arsenito de sodio condujo a una pérdida de la viabilidad de los esplenocitos dependiente de la dosis, lo que confirma que son células diana de la inducción de muerte celular por los compuestos arsenicales (17).

Posteriormente, se midieron las concentraciones de hierro y polifenoles en las muestras orgánicas obtenidas de los animales experimentales y, al analizar la concentración de polifenoles, se observó una disminución tisular de estos compuestos en el bazo y el timo de los animales tratados con arsénico. Esto indica un posible agotamiento de los polifenoles provenientes 
de la dieta cuando los animales son tratados con el arsenito de sodio (18). Se encontraron resultados análogos en el bazo tras determinar la concentración de hierro, lo que corroboró la disminución de los niveles de este mineral con la administración de arsénico, lo cual podría explicarse por el desplazamiento del hierro hacia la corriente sanguínea o el espacio intersticial movilizado por la capacidad de lisis del arsénico (19). En este sentido, otros autores han reportado el efecto directo que tiene la bioacumulación de arsénico en el contenido y la distribución del hierro en los tejidos hemolinfáticos e, indirectamente, en la homeostasis de otros metales como el cobre, el cinc y el manganeso $(20,21)$, lo cual compromete las reacciones enzimáticas de las células y contribuye a la inmunodeficiencia inducida por arsénico.

Además, se midió la formación de peróxidos acuoso y lipídico, y de productos avanzados de oxidación proteica en los tejidos de ambos grupos, y se encontró que la dosis de arsenito de sodio solo resultó en un aumento del peróxido acuoso en el riñón. Con la dosis de arsenito inyectada, se constató que la inducción de estrés oxidativo no sería la vía involucrada en la disminución de la viabilidad de los esplenocitos y, en una primera aproximación, los resultados indican una muerte celular temprana, sin variación en las mediciones de la oxidorreducción (22).

Por otra parte, con la administración de arsénico, la concentración de grupos sulfhidrilos en el bazo tendió a disminuir en comparación con el control, lo que se vio confirmado por la capacidad de los arsenicales trivalentes de interactuar con los grupos tioles de péptidos y proteínas, tales como el glutatión celular (GSH) y diversas enzimas y cofactores, y de inhibir su acción (23). No obstante, este efecto no se observó en el timo, donde la concentración de sulfhidrilos libres se elevó en el grupo con arsénico, probablemente como resultado de una diferenciación en el proceso de biotransformación que tiene lugar en ambos tejidos, a partir del cual el ácido metilarsónico se concentra en el timo, según lo observado por Xu, et al.; estos autores describen aumento de la capacidad de este metabolito para inducir genotoxicidad y apoptosis en dicho tejido (24), aunque se diferencia del arsénico trivalente en su selectividad por la interacción con los grupos tioles $(25,26)$.

Por último, se observó una reducción en el potencial de la membrana mitocondrial de los esplenocitos obtenidos del grupo con arsénico en comparación con el de control. En este sentido, en varios estudios se plantea que el arsénico es un poderoso tóxico para la mitocondria con base en su capacidad de inducir apoptosis a partir de la acción directa sobre la cadena respiratoria mitocondrial y el poro de transición mitocondrial (mPTP) (27), lo cual aumenta la permeabilidad de las membranas interna y externa de la mitocondria, la liberación del citocromo $\mathrm{C}$ y la activación de las caspasas 9 y 3 (28). Consecuentemente, este evento deriva en una disminución del ATP y en la muerte celular (29), lo cual también explica la caída de la viabilidad observada en el presente trabajo.

En conjunto, los resultados brindan evidencia fehaciente de que la administración aguda en monodosis de arsenito de sodio reduce la función mitocondrial de los esplenocitos, lo que modularía la muerte celular, revalidando así la reconocida actividad citotóxica de los compuestos arsenicales $(30,31)$. Además, se demostró que los mecanismos de toxicidad de esta sustancia involucran disminución en los niveles de polifenoles, y alteración en el contenido de sulfhidrilos libres y la distribución de hierro en perjuicio de los tejidos estudiados. 
Los hallazgos del presente estudio aportan evidencia científica sobre los cambios en los biomarcadores involucrados en la inmunotoxicidad del arsénico y ofrecen, además, un diseño experimental específico para ensayar potenciales tratamientos frente a la acción deletérea del arsénico trivalente y sus derivados en el sistema inmunitario.

\section{Agradecimientos}

El trabajo recibió el apoyo y la financiación del Consejo Nacional de Investigaciones Científicas y Técnicas (CONICET) y de la Universidad Nacional de Córdoba, Argentina (SECYT).

\section{Referencias}

1. Grinyó JM, Cruzado JM, Bestard O, Vidal-Castañeira JR, Torras J. Immunosuppression in the era of biological agents. Adv Exp Med Biol. 2012;741:60-72. https://doi.org/10.1007/978-1-4614-2098-9 5

2. Ferrario D, Gribaldo L, Hartung T. Arsenic eExposure and immunotoxicity: A review including the possible influence of age and sex. Curr Environ Health Rep. 2016;3:1-12. https://doi.org/10.1007/s40572-016-0082-3

3. Cordero H, Morcillo P, Martínez S, Meseguer J, Pérez-Sirvent C, Chaves-Pozo E, et al. Inorganic arsenic causes apoptosis cell death and immunotoxicity on European sea bass (Dicentrarchus labrax). Mar Pollut Bull. 2018;128:324-32. https://doi.org/10.1016/i.marpolbul.2018.01.052

4. Hughes MF, Beck BD, Chen Y. Arsenic exposure and toxicology: A historical perspective. Toxicol Sci. 2011;123:305-32. https://doi.org/10.1093/toxsci/kfr184

5. Acharya S, Chaudhuri S, Chatterjee S, Kumar P, Begum Z, Dasgupta S, et al. Immunological profile of arsenic toxicity: A hint towards arsenic-induced carcinogenesis. Asian Pac J Cancer Prev. 2010;11:479-90.

6. $\mathrm{Ng} \mathrm{JC}$. Environmental contamination of arsenic and its toxicological impact on humans. Environ Chem. 2005;2:146-60. https://doi.org/10.1071/EN05062

7. Miranda AR, Soria EA. Análisis proteasomal y multidimensional en quimioencefalopatía aguda inducida por arsénico trivalente en ratones y neuroprotección por ácido clorogénico. En: INC. Becas de investigación en cáncer 2015-2016: Informes finales de estudiantes avanzados y graduados. Primera edición. Ciudad Autónoma de Buenos Aires: Instituto Nacional del Cáncer; 2017. p. 73-84.

8. Pérez RD, Falchini GE, Cometto-Vincente F, Soares L, Poletti ME, Sánchez HJ. A new spectrometer using a crystal monochromator and parallel plates beam guides. Nuc Istr Meth. 2019;440:48-53. https://doi.org/10.1016/j.nimb.2018.11.030

9. Chen JL, Steele TWJ, Stuckey DC. Metabolic reduction of resazurin; location within the cell for cytotoxicity assays. Biotechnol Bioeng. 2018;115:351-8. https://doi.org/10.1002/bit.26475

10. Ait Baddi G, Cegarra J, Merlina G, Revel JC, Hafidi M. Qualitative and quantitative evolution of polyphenolic compounds during composting of an olive-mill waste-wheat straw mixture. J Hazard Mater. 2009;165:1119-23. https://doi.org/10.1016/j.jhazmat.2008.10.102

11. Pieroni G, Khalil L, Charlotte F, Poynard T, Piton A, Hainque B, et al. Comparison of bathophenanthroline sulfonate and ferene as chromogens in colorimetric measurement of low hepatic iron concentration. Clin Chem. 2001;47:2059-61.

12. Soria EA, Goleniowski ME, Cantero JJ, Bongiovanni GA. Antioxidant activity of different extracts of Argentinian medicinal plants against arsenic-induced toxicity in renal cells. Hum Exp Toxicol. 2008;27:341-6. https://doi.org/10.1177/0960327108092192

13. Piwowar A. Advanced oxidation protein products. Part I. Mechanism of the formation, characteristics and property. Pol Merkur Lekarski. 2010;28:166-9.

14. InfoStat. InfoStat versión 2018. Córdoba: Universidad Nacional de Córdoba; 2018.

15. Rubatto-Birri PN, Pérez RD, Cremonezzi D, Pérez CA, Rubio M, Bongiovanni GA. Association between As an Cu renal cortex accumulation and physiological and histological alterations after chronic arsenic intake. Environ Res. 2010;110:417-23.

https://doi.org/10.1016/j.envres.2009.09.002 
16. Soria EA, Pérez RD, Queralt I, Pérez CA, Bongiovanni GA. Immunotoxicological effects of arsenic bioaccumulation on spatial metallomics and cellular enzyme response in the spleen of male Wistar rats after oral intake. Toxicol Lett. 2017;266:65-73. https://doi.org/10.1016/j.toxlet.2016.12.014

17. Patra PH, Bandyopadhyay S, Bandyopadhyay MC, Mandal TK. Immunotoxic and genotoxic potential of arsenic and its chemical species in goats. Toxicol Int. 2013;20:6-10. https://doi.org/10.4103/0971-6580.111533

18. D'Archivio M, Filesi C, Varí R, Scazzocchio B, Masella R. Bioavailability of the polyphenols: Status and controversias. Int J Mol Sci. 2010;11:1321-42. https://doi.org/10.3390/ijms11041321

19. Mahmud H, Föller M, Lang F. Arsenic-induced suicidal erythrocyte death. Arch Toxicol. 2009;83:107-13. https://doi.org/10.1007/s00204-008-0338-2

20. Wang $L, X u Z R$, Jia $X Y$, Han $X Y$. Effects of dietary arsenic levels on serum parameters and trace mineral retentions in growing and finishing pigs. Biol Trace Elem. 2006;113:155-64. https://doi.org/10.1385/BTER:113:2:155

21. Cui X, Okayasu R. Arsenic accumulation, elimination and interaction with copper, zinc and manganese in liver and kidney of rats. Food Chem Toxicol. 2008;46:3646-50. https://doi.org/10.1016/j.fct.2008.09.040

22. Montelescaut E, Vermeersch V, Commandeur D, Huynh S, Danguy des Deserts M, Sapin J, et al. Acute arsenic poisoning. Ann Biol Clin (Paris). 2014;72:735-8. https://doi.org/10.1684/abc.2014.1012

23. Watanabe T, Hirano S. Metabolism of arsenic and its toxicological relevance. Arch Toxicol. 2013;87:969-79. https://doi.org/10.1007/s00204-012-0904-5

24. Xu H, Medina S, Lauer FT, Douillet C, Liu KJ, Stýblo M, et al. Genotoxicity induced by monomethylarsonous acid $\left(\mathrm{MMA}^{+3}\right)$ in mouse thymic developing $\mathrm{T}$ cells. Toxicol Lett. 2017;279:60-6. https://doi.org/10.1016/j.toxlet.2017.07.897

25. Xu H, McClain S, Medina S, Lauer FT, Douillet C, Liu KJ, et al. Differential sensitivities of bone marrow, spleen and thymus to genotoxicity induced by environmentally relevant concentrations of arsenite. Toxicol Lett. 2016;262:55-61. https://doi.org/10.1016/j.toxlet.2016.09.008

26. Zhou X, Sun X, Mobarak C, Gandolfi AJ, Burchiel SW, Hudson LG, et al. Differential binding of monomethylarsonous acid compared to arsenite and arsenic trioxide with zinc finger peptides and proteins. Chem Res Toxicol. 2014;27:690-8. https://doi.org/10.1021/tx500022j

27. Pelicano H, Feng, L, Zhou Y, Carew JS, Hileman EO, Plunkett W, et al. Inhibition of mitochondrial respiration: A novel strategy to enhance drug-induced apoptosis in human leukemia cells by a reactive oxygen species-mediated mechanism. J Biol Chem. 2003;278:37832-9. https://doi.org/10.1074/jbc.M301546200

28. Belzacq AS, El Hamel C, Vieira HL, Cohen I, Haouzi D, Metivier D, et al. Adenine nucleotide translocator mediates the mitochondrial membrane permeabilization induced by lonidamine, arsenite and CD437. Oncogene. 2001;20:7579-87. https://doi.org/10.1038/sj.onc. 1204953

29. Skulachev VP. Bioenergetic aspects of apoptosis, necrosis and mitoptosis. Apoptosis. 2006;11:473-85. https://doi.org/10.1007/s10495-006-5881-9

30. Moe B, Peng H, Lu X, Chen B, Chen L, Gabos S, et al. Comparative cytotoxicity of fourteen trivalent and pentavalent arsenic species determined using real-time cell sensing. J Environ Sci (China). 2016;49:113-24. https://doi.org/10.1016/j.jes.2016.10.004

31. Rahman MT, De Ley M. Arsenic induction of metallothionein and metallothionein induction against arsenic cytotoxicity. Rev Environ Contam Toxicol. 2017;240:151-68.

https://doi.org/10.1007/398 20162 